Article

\title{
Local Productive Systems' Transitions to Industry 4.0+
}

\author{
Marco Bellandi ${ }^{1, *}$ [D and Lisa De Propris ${ }^{2}$ \\ 1 Department of Economics and Management, University of Florence, 50127 Florence, Italy \\ 2 Department of Management, University of Birmingham, Birmingham B15 2TT, UK; 1.depropris@bham.ac.uk \\ * Correspondence: marco.bellandi@unifi.it
}

check for

updates

Citation: Bellandi, M.; De Propris, L. Local Productive Systems' Transitions to Industry 4.0+. Sustainability 2021, 13, 13052. https://doi.org/10.3390/ su132313052

Academic Editor: Wen-Hsien Tsai

Received: 16 October 2021

Accepted: 21 November 2021

Published: 25 November 2021

Publisher's Note: MDPI stays neutral with regard to jurisdictional claims in published maps and institutional affiliations.

Copyright: (C) 2021 by the authors. Licensee MDPI, Basel, Switzerland. This article is an open access article distributed under the terms and conditions of the Creative Commons Attribution (CC BY) license (https:// creativecommons.org/licenses/by/ $4.0 /)$.

\begin{abstract}
The paper is positioned in the emerging debate on the technological change brought about by the Fourth Industrial Revolution, often referred to as Industry 4.0. Our analysis is at the local, sub-national level. The aim is to explore what drivers and barriers local productive systems might face when seeking to embark on transitions that reconcile smart, equitable, and sustainable priorities, under enhanced models called Industry 4.0+. The novelty of the paper is to develop such models by designing a conceptual framework that juxtaposes the drivers and the barriers of sustainability transitions with local productive systems. This novel framework suggests possible pathways that local productive systems can initiate to achieve more equitable and green outcomes for their economy and society by directing the development of digital-related solutions.
\end{abstract}

Keywords: local productive systems; digital transition; green transition; Industry 4.0+

\section{Introduction}

The recent literature on Industry 4.0 has focused on a subset of new technologies, including machine learning and artificial intelligence, mobile tech, 3D, robotics, sensoring and space tech, autonomous vehicles, and drones [1]. These technologies are expected to deliver more efficiency in production and use, as well as better connectivity and functionality across a broad spectrum of devices, from smart watches on our wrists to entire cyber-physical systems in factories. Indeed, this is half of the story, which, per se, would not change the world [2]. What will make a real difference is the growing wave of combinations of digital technologies with a broader set of innovations and transformations, including, on one hand, nano- and bio-technologies (NBT), ranging from biogenetics and neuro-technologies to green and renewable technologies [3]; and on the other hand, those related to social and institutional innovations and changes in business models and workers, as well as consumers' and citizens' behaviors [4]. This is the emerging Fourth Industrial Revolution (FIR) [2].

The actual and potential pervasiveness of the FIR wave has raised the question of its impact not only on the prospects of smarter productive processes, goods, and services, but also on the social and environmental agenda at local, national, and international levels, in view of addressing contemporary challenges in terms of sustainable development [1]. There is an open debate on what model digital transitions could be assumed in contemporary productive and innovation systems. One could advocate for the adoption of solutions where trade-offs between smart, social, and green goals are managed and positive complementarities are sought via socially responsible private strategies, whether individual or collective, and sensible public policies. Or instead, one could endorse more laissez-faire approaches where the same trade-offs and complementarities are addressed by pure economic interests and market dynamics and the protective net of the welfare state is used as a last resort $[4,5]$. The former approach to the search for equitable and sustainable solutions draws on the belief that a certain degree of collective and public leadership and regulation is needed for transitions that point to green [6] (pp. 24-25) as well as digital transformations.

This paper contributes to a nascent debate that is acknowledging the need to reconcile smart, social, and green goals under sustainability transitions in productive and/or 
innovation systems [1] (Chapter 1). In the European Union, for example, this debate is liaising with the recent push of policies to endorse a holistic approach and is captured by the terms "Industry 5.0" [5] or "Smart specialization strategies for sustainable and inclusive growth" [4]. Although sustainability transitions confront an internal or external competitive environment often attuned to market logic only, equitable solutions require a place-based foundation [4]. The focus of the paper on Local Productive Systems (LPSs), like industrial districts primarily characterized by SMEs [7], allows us to investigate the strengths and weaknesses of such a foundation.

We build specifically on the concept of "Industry 4.0+" (or I4.0+) proposed in the EU project, MAKERS [1,8] (see all EU Commission reports at www.makers-rise.org/home/, accessed on 23 November 2021), as a novel model to capture the systemic change that all FIR technologies can engender. Comprising a positive and normative 'system' perspective, it developed applications to system and place-based units of investigation, such as LPSs, as well as to global networks of production often organized by large multi-national firms [1] (p. 3). MAKERS studies, however, addressed the digital and social dimensions of transitions, neglecting the integration of the environmental dimension, or vice versa [9]. Overall, there appears a gap in the identification of the problems of sustainability transitions led by comprehensive I4.0+ models in contemporary LPSs, which we propose to try and fill, referring mainly to the EU context.

The novelty of the paper is, therefore, to present a conceptual framework that identifies what factors might promote or hinder the opportunity of LPSs to transition onto I4.0+ models of sustainability, that reconcile digital, social, and green dimensions within their place-based industrial organization. More precisely, we will explore how I4.0+ models might enter possible sustainability transitions of LPSs and identify such models as types of "sustainable development in clusters and regional innovation systems" (according to the title of this Special Issue). The window of opportunity for I4.0+ in a LPS needs appropriate multi-level policies of productive development and innovation, such as those identified in Industry 5.0 and S4+ approaches, and their combination with favorable local factors and individual and collective actions. The paper complements the sectoral and regional views of such approaches with an explicit industrial organization and political economy view, where internal and external barriers to "value creation and value capture" in LPSs [10] strengthen dominant competing I4.0 models and weaken I4.0+ take-off or rerouting [8].

Building on the original findings of MAKERS studies, a critical review of the current relevant debate will be integrated with two important and related concepts, namely Sustainable Regional Innovation Systems and Quintuple Helix innovation partnerships [11-13]. These allow a consistent inclusion of the agency dimension within comprehensive I4.0+ models. Indeed, they both refer, together with business, university, and governmental actors, to actors related to civic society and environmental protection, which collaborate on and hybridize place-based innovation and developmental purposes.

The paper will proceed as follows. A review of the relevant literature will introduce the framework hosting a comprehensive I4.0+ model, its drivers and barriers, and a novel qualitative taxonomy of possible sustainable transitions that LPSs could follow towards I4.0+. The reference to a few selected cases will help illustrate the meaning of the taxonomy and its broader applicability. The conclusions will refer back to policies and governance, together with prospects of future research.

\section{A Literature Review}

\subsection{Digital Transformation and Sustainability Transitions of Local Productive Systems}

The necessity for sustainable economic development to be socially inclusive and environmentally reproductive in the long run was already clearly stated at the international level in 1987, by the Brundtland Report of the UN World Commission on Environment and Development [14]. This statement slowly trickled down in policy guidelines of supranational, national, and regional governments. Considering the context of the European Union, for example, since 2000, "the EU's growth and development strategy has centred around the 
achievement of smart and inclusive growth as in the original Lisbon formulation to which sustainability was subsequently added and later on in 2010 translated into the creation of a 'smart, sustainable and inclusive economy', known as 'Europe 2020'” [4] (p. 13). Beyond Europe, contributions on green economy, environmental justice, and just sustainability have started linking the ecological agenda with social justice in other advanced and industrializing economies, as well as in developing economies where communities have been more severely hit by the impact of climate change $[15,16]$.

In the last decade, failure in the implementation of such advocacy for sustainable development, in Europe and elsewhere, has created a contested space on whether the three-way intersection amongst environmental sustainability, inclusivity, and digitalization is characterized by complementarities rather than trade-offs [4] (p. 14), adding specific difficulties to those that generally feature sustainability transitions [6]. Indeed, even just the pairwise relationships between growth and sustainability, as well as between technological change and inclusivity, raise problems. For example, a quite recent piece of literature, resuming an old tradition in political economy, explores the economic benefits of automation and digitalization in terms of efficiency as well as costs, especially in terms of jobs losses and skills mismatch $[17,18]$.

The MAKERS studies recalled in the introduction above have contributed to this debate, pointing out the need to identify alternative models of industrial organization and digital transitions that the I4.0 and, more generally, the FIR technologies have been opening to. The Industry 4.0+ (I4.0+) model delineated in such studies is meant to draw a field of digitally related transitions in productive and innovation systems consistent with sustainability transitions [9]. The "deployment of all the technologies of the FIR will trigger a transformational shift in the techno-socio-economic paradigm attuned to a green economy and society. Only a holistic definition of Industry 4.0+ can deliver opportunities for inclusive socioeconomic growth." [1] (p. 9). Indeed, greater automation and connectivity in manufacturing processes and products, as in the original propositions of Industry 4.0 or related concepts like "smart industry" or "smart manufacturing" [19] (p. 2), are not enough. It is necessary to move beyond technocratic models of Industry 4.0, where digitalization and automation are seen as the exclusive dominant drivers of change, and to point out a broader set of dimensions of technology which offers a holistic approach to developmental alternatives to Industry 4.0. A founding question on such alternatives is [8]: Do the exploration and exploitation of Industry 4.0 potentials need a polarization of knowledge, decision-making power, capital, industries, and places, driven by efficiency arguments? Or is a variety of competitive solutions feasible, including alternatives consistent with virtuous circles between parts of the technological wave potentialities and a wide mobilization of human capabilities respectful of environmental constraints?

I4.0+ is proposed precisely as a set of models substantiating such holistic alternative. They join FIR technologies with product-service solutions in new and traditional industries, dynamic competition in differentiating markets, business models based on digital platforms and user-producer innovations, large populations of skilled workers matching goods jobs featured by new worker-machine relations, a fair distribution of income opportunities, room for bottom-up productive and socio-cultural creativity, smart solutions to environmental problems, inclusive local societies, and resilient territorial systems [1]. By contrast, development paths led by oligopolistic and technocratic models of Industry 4.0, under the first alternative, may feature high economic efficiency but a low attention to the distributive, social, and environmental qualities of sustainability [8], apart from green washing communication strategies.

An implication of I4.0+ models is that their disruptive potential for opening windows of sustainable techno-socio-economic paths cannot be entrusted exclusively to the pure market aggregation of individual investments. Such opportunities will not automatically translate in real-world solutions, or at least they could have a limited penetration if their systemic nature was not understood or was underplayed in individual and collective strategies. I4.0+ models need to come with appropriate regulative supports. The MAKERS 
studies suggested a place-based view of such supports, liaising with a large literature on local productive systems (LPS) [7] and on regional policies of productive development and innovation [20].

Indeed, the literature on technological and sustainable transitions, grown with the aim to unpack what processes and what factors drive industries to transition from one technological paradigm to the next [6], has framed its contributions in the wider innovation literature on system change [21], suggesting that technological revolutions do not impact on one sector or the other, but trigger a disruptive change in the techno-economic system. One of the main limitations of this literature is that it is mostly space blind. Only recently has the work on ecological transitions acquired a clear spatial connotation, as some early conceptual advancements [22] have been coupled with illustrative examples of cities or regions $[23,24]$. There are at least three reasons that justify the adoption of the place-based view in MAKERS studies [1].

(a) First, an inclusive application of Industry 4.0 would make room for understanding opportunities for millions of SMEs populating the European economies and worldwide. Within the millions, a non-small number can play as innovators, though constrained by uncertain market channels, difficult access to finance, restricted pool of internal skills, strategies of command, and control by oligopolistic concentrations of technological and economic power. Such constraints can be alleviated precisely by embedding or anchoring a population of specialized SMEs in a place, where they more easily develop a division of labor thanks to cognitive and geographical proximity [25]. Such system features are clearly exemplified by territories hosting Local Productive Systems (LPSs) and Regional Innovation Systems (RISs). LPSs correspond to delimited places (e.g., counties; daily urban areas) featuring parts of value chains, with their local core being organized in one or few business clusters that are possibly, but not necessarily, all led by specialized SMEs [1] (p. 3) [7]. A RIS may comprise one or more LPS and other types of local systems and is featured by a high degree of "network connectivity" [12] (p. 29) between business actors, public governments, higher education, and research institutions, for promoting fruitful cognitive exchanges, expanding cross-learning opportunities, and pushing technological and socio-cultural innovation $[13,26]$.

(b) The second reason comes from the fact that the overlapping of work and out-of-work experiences in a place, which tends to be structurally dense and regular in LPSs, represents a natural living lab for entrepreneurs to understand and develop the interpenetration of new technologies and a multiplicity of individual and collective needs. This is because the specificity and differentiation of such needs often find their sourcing code in the variety of historical-cultural heritages and environmental features of places [27]. FIR technologies show great potentials in terms of customization and cross-fertilization of various fields of life, local and non-local [2].

(c) The third reason is at the intersection of the first two. A variety of coordinated policies can be key in deliberating regulative supports of sustainable transitions. Placebased policies focus directly on the constitution or reproduction of collective and public goods specific to the needs of a local population of independent producers and active citizens $[28,29]$. Appropriate schemes of multi-level governance can operate here, helping the definition, implementation, and impacts of policies, thanks to both the involvement of the local community and the coordination with upper levels of public action [20], as well as with the private action of large firms leading global value chains [1].

A couple of contributions aiming at the EU context of regional policies, and largely consistent with the MAKERS premises, helps expand the implications of I4.0+. As already recalled in the introduction above, one proposes the concept of S4+ [4] and the other adopts and expands on the concept of Industry 5.0 [5]. Both contributions reflect on the underpinnings of the latest grand strategic narrative in the EU, the European Green Deal (EGD), and its application to recovery and resilience after the outbreak of COVID-19, with the Next Generation EU. They argue, underlining either sectoral conditions or regional ones, the priority that should be given, by means of deliberate policies and multi-level 
governance schemes operating in the EU space, to sustainability priorities incorporating digital imperatives.

Industry 5.0 relates to solutions or transitions that can emerge by directing Industry 4.0 technologies to production organizations, consistent with "human-centric", environmentally "sustainable", and socially "resilient" purposes [5] (p. 14). A set of specific policies, for example within the EGD, should exploit alternative and selective incentives that have different expressions in different sectoral socio-technical systems. A complementary view is proposed by [4] with the "Smart specialization strategies for sustainable and inclusive growth", suggesting a shift from S3 (smart specialization strategies) to S4+ in regional innovation systems. Here, the regional strategies of qualification and upgrading of local productive and innovative specializations in the European space should point out accelerating processes of entrepreneurial discovery towards penetration of both digital and green solutions. It is argued that the penetration should be place-based, cross-disciplinary research- and innovation-driven, as well as respectful of the sustainability priority: "The EGD requires that ultimately 'smart' should not be leading in science, technology and innovation but 'sustainability'" [4] (p. 15). The collective and public support of such solutions should encourage place-based projects under multi-level governance schemes and strategic top-down coordination.

\subsection{Greening Local Productive Systems and Sustainable Regional Innovation Systems}

The specific focus on LPSs allowed MAKERS studies to direct interpretative efforts to the conditions of "value creation" and "value capture" for open sets of business, labor, and societal actors operating at the local or regional level [10]. Value creation realized in an LPS depends significantly on productive factors that are embedded, or at least anchored, in the place. Value capture by the LPS implies that a significant part of the value created, because of the productivity of local factors, remains under the control of local actors or at least is re-invested in local factors. Neither value creation nor value capture are granted in significant amounts for an LPS that tries to reroute towards a new path of development, even less when a digital-led or digital-related sustainability transition is involved. Indeed, as argued previously in Section 2.1, the success of a sustainable transition should be seen as connected precisely to the preservation or re-constitution of the condition of significant value creation and value capture for actors and territories involved.

- Most deliverables of MAKERS studies on sustainable transitions concerned combinations of smart (digital-based) and inclusive solutions [1]. In a follow-up, [8] illustrates drivers and barriers for such transitions in LPS, without making explicit the intersection with factors related to the greening of industry and the territorial ecological modernization. Drivers and barriers are referred specifically to cost minimization and revenue maximization (value creation for business actors), labor relations (value creation for workers), market forms and corporate responsibility (value capture for business actors), and governance and public directionality (value capture for social actors). Summarizing on [8]:

- The drivers of combinations of smart and inclusive solutions in LPS include interdependent and new manufacturing know-how nuclei within and around smart micro plants, territorial servitization provided by local or localized KIBS, neo-makers skills supplementing local pools of traditional blue collar and artisan skills, and participatory projects of territorial digital transformation that involve partnerships of firms, universities, governments, and civic actors.

- Barriers concern incentive misalignment between local actors, new types of local transaction costs, incumbency of dominant technocratic models, digital-based monopolistic dominance of large firms within global value chains where the LPS participates, and the short-run profit and power drives that are expanding skill polarization in the workplace and local digital divides in projects of smart cities.

Our understanding of how digital and green transitions combine in specific LPSs is still limited. However, some case studies have started to shed some light on the main 
attributes of placed-based green transitions. Referring to a contribution again included in the MAKERS studies [9], it is possible to identify four broad categories of such attributes: (a) the presence of knowledge transversality; (b) the systemic nature of the transition; (c) the multi-scalar dimension of the transition; and d) the role of agency and policy.

(a) Firstly, the broad opportunities for green transitions stem from the fact that the knowledge base is characterized by transversality, spanning a broad "related variety" [30]. This transversality is reflected by the potentially pervasive nature of environmental innovation, well-defined in a Report of the EU: "eco-innovation is any innovation that reduces the use of natural resources and decreases the release of harmful substances across the whole lifecycle (..). Eco-innovation can be found in all forms of new, or significantly improved, products, goods, services, processes, marketing methods, organisational structures, institutional arrangements and lifestyle and social behaviours, which lead to environmental improvements compared to relevant alternatives" [31] (p. 29). Therefore, it is not surprising to find cases pointing out greening LPS (districts or clusters) in every productive sector, from those specialized in the elaboration of biological resources [32-34] and mineral and artificial materials [23], to clean-tech clusters [12] as well as ICT clusters, to service sectors related to cultural goods, such as local tourism systems [35].

(b) Secondly, green transitions require much more than the aggregation of a pool of piecemeal innovations, be them by market or public command. Like digital transitions, they imply also important systemic features. The question is that effective sustainability outcomes imply control of the "whole life cycle" of products and services within the different value chains that are involved. A quote from [32], even if addressed specifically to bio-clusters, makes this point more generally: "If we view a biocluster as a combination of different value chains that are, at least partly, located within the same region, the environmental sustainability of the bio-cluster is related to the question of how these value chains are organised: where does a bio-cluster obtain its inputs, how does it process them, what are the sustainability effects related to the use of its main products and processes, and ultimately, how are waste and recycling organised?" [32] (p. 82). The same questions could be related to the transition from the "linear economy" (extract, consume, dispose) to the "circular economy" (reduce, reuse, recycle) [31] (p. 29). Indeed, the wholeness of the environmental impacts and the circular solutions generate opportunity for cognitive complementarity within the different value chains and phases where delimited environmental innovations can be applied. Transversal and systemic features allow for recombinant innovation, opening windows of opportunity to radical or even transformative impacts in sectors and places [12]. However, one must be aware of barriers related to inertial local, organizational, and sectoral factors that can block effective sustainability transitions (e.g., due to the heavy sunk costs of some territorial infrastructures) [4], and figure out strategies to unlock them [36].

(c) The third important attribute of green transitions is that they stretch across multiscalar territorial, sectorial, and institutional levels. It is true that ecological problems tend to have possible global spillovers and fallouts. However, consider the same barriers to environmental innovations, which have often a clear place- or sectoral-based nature [5]. The relevance of such problems is reflected in the reference made in [9] to interpretative constructs, such as the socio-technical systems and the multi-level perspective of dialectics between incumbent configurations (regimes) and potential upcoming configurations (niches) within meta-context or landscape constraints [6]. As recalled above, recent contributions are exploring the territorial embedding of such multi-level sectoral and institutional dialectics [24]. Some dialectics impinge more directly on the territory of a single LPS. In the middle, various geographical, historical, and administrative borders delimit fields where impacts and cognitive complementarity may be differently perceived and acted upon by public policies and private strategies. Related dynamics and conflicts unfold within various networks and at different territorial levels, involving the value chains of multinational companies as much as regional and national public and societal agencies. Considering specifically LPSs, a couple of implications must be pointed out: 
- On one side, by definition [7,8], LPSs are places where the residentiary and out-ofwork life overlaps in delimited territories with the economic activities of entrepreneurs, employees, and professionals in the industry characterizing the LPS. This can create a concentration of potentially polluting productive and dwelling activities. Therefore, some environmental impacts of the productive activities of an LPS can be felt more directly by local groups of people that combine producers, users, citizens, and institutional actors [37]; consequently, the transversality of environmental innovation extends directly to "territorial oriented innovations" promoted by innovative milieus impinging on such groups [35] (p. 7).

- On the other side, again by definition, a LPS features a high level of productive specialization; in other words, it comprises entire or segments of value chains in one or a few business clusters, amounting to a delimited typology of complementary know-how nuclei. The range of cognitive exchanges enlarges when a RIS including the LPS and other places is active. If such exchanges are systematically applied to transversal environmental problems and solutions, thanks to the support of embedded intermediary functions, the potentiality of green innovations increases. These are forms of "sustainable regional innovation systems" [13], which rest on the crossfertilization of different (technologically related or unrelated) regional specializations, the so-called "Jacobian" (from J. Jacobs) effects [12].

(d) Fourthly, a last attribute of green transitions lies, therefore, underneath their systemic and multi-scalar nature; agency and strategy necessarily shape the non-deterministic outcomes of the structural dynamics and system change at the heart of green transitions [6]. When considering LPSs, one must bear in mind the more-or-less extended plurality of specialized productive organizations therein comprised, and often the presence of a quite large population of SMEs. This makes it necessary for sets of public-like goods to be available to support the private operations of such plurality. Examples include pure public goods such as green performance labels and certificates (e.g., EMAS); club goods, such as collective water purifiers; or again, common-pool resources, such as public green and subsoil water reservoirs [28]. Some of them extend to or concern residentiary life, as already recalled [35]. Though public-like, their functions may be somehow specific or adapted to the local productive and social needs [37]. Indeed, the specific features of such public goods are necessary for the collective efficiency of the LPS, and for its collective capability to increase the local environmental sustainability [35]. The consideration of public goods specific to green transitions in LPS helps draw at least three qualifications.

- An appropriate provision of public-like goods specific to the environmental sustainability of an LPS and its territory requires a leadership able to mobilize public and collective resources. The mobilization may strictly follow the lines of public bureaucracies. However, it is well known that this is just a last resort solution. The adaptations to specific needs imply a fine-grained knowledge of constraints, opportunities, and interests, diffused among sets of different stakeholders. Their participation, directly or by means of representative leaders, in the design, funding schemes, building, provision, and management of specific public-like goods may improve the quality of knowledge, as well as have multiplicative effects, thanks to complementary private resources. This means governance methods that involve, in various ways, different types of multi-actor partnerships, possibly driven by a place leadership [38]. An open and constructive place leadership can support participatory methods and partnerships [39] that make specific public-like goods, in a way, a collective ownership, i.e., "commons" for the LPS and its territory $[29,40]$.

- Openness and constructive approaches would need the presence of parties, intermediary agencies, and regulative bodies, which might allow going beyond a localist, conservative, and short-terminist representation of environmental challenges [4]. According to a stream of literature on the organization of innovation, partnerships that support systemic innovation need to include business, university, and government actors (the triple helix [41]), as well as civic actors and representatives of the reproduc- 
tive needs of the natural capital (the fourth and fifth helices [42-44]). It is to be noted that the last type of actors necessarily also has connections outside the local system. A well-functioning partnership will host both operative actors with hybrid features and intermediary organizations based on multi-disciplinary and trans-disciplinary approaches [45-48]; they both will help develop environmental innovation projects on truly transversal bases [42,47]. The regional level of governance, if equipped with adequate regulative power and resources, will support such partnerships because it may show a good compromise between autonomy from parochial interests and a good understanding of how lower local levels may express constructive alliances $[31,49]$. The right level depends also on the width of innovation and its phase of development. More transformative innovations, especially transiting from niche to new regime, will probably need a stronger cooperation between the regional and the national, if not upper, levels of governance $[26,50,51]$. An example of this is the proposal of S4+ recalled in Section 2.1 [4]. Other examples are "institutional oriented" environmental innovations and "flagship oriented" ones, complementary to product, process, and territorial innovations, which impinge on variable, but not exclusively local, innovative milieus [35] (p. 7).

- Again, the impact of conflictual interests is not to be underestimated at the level of individual and social groups, nor is the difficulty in managing them. Furthermore, in principle, when environmental sustainability is involved, the biggest problem comes from ignoring the side of silent stakeholders, such as future generations and far-away territories that are affected by natural resources and climate crises [52]. Indeed, governance may be fragmented, and place leadership shows approaches less than constructive, even rent-preserving and short-terminist [39]. Regressive coalitions struggling for place leadership, or at least acting to block constructive coalitions, might have the possibility to involve ugly allies, e.g., intermediaries that help delocalize or export environmentally damaging parts of the value chain to less-regulated countries or regions [53]. The presence of eco-criminal organizations [54] cannot be excluded; they take the task of dismissing environmental regulations, for example via the illegal disposal of dangerous waste or over-exploitation of migrant workers, both in the LPS and around it. On the other side, the sustainability agenda may be charged with political ideology, for example with environmental ideals being supported by visions of natural states, rather than scientific evidence and solid theories of territorial planning [52]. The outcomes of the prevalence of such coalitions in local and regional governance could lead to "lock-in", delivering ecological and economic decline or degradation to "dirty" paths of development [55].

The importance of the four attributes of placed-based green transitions is confirmed by general readings of environmental innovations and sustainability transitions in regional studies [12,22,24]. Different streams of related contributions articulate the four sides. Drawing on this critical review of the current debate, the next section extracts a set of meaningful intersections between smart, social, and green goals, and draws a conceptual framework that explicitly integrates environmental issues within I4.0+ models of sustainability transitions for LPSs.

\section{A Comprehensive Sustainability Framework of I4.0+ Transitions in LPS}

In the previous sections, we have argued that greening industry and environmental sustainability opportunities may be observed in a large variety of types of LPSs, some of which might be just adapters of solutions, whilst others might be able to become creators of new solutions in their socio-technical niches. I4.0 opportunities have a multi-purpose and key enabling nature, thereby diffusely penetrating the worlds of LPS according to different models. I4.0+ models for LPS sustainability transitions could be seen as an alternative to technocratic models of digital organization of productive systems and cities, witnessing an emerging monopolistic dominance of large digital firms within global value chains (obviously, the real world is much more complicated than the one drawn by few 
ideal types). Finally, a conceptual framework of a partial I4.0+ model combining digital transformation with social sustainability is available, but a comprehensive framework also hosting the combination with the environmental side is lacking until now.

What are the distinctive features that must be added to the partial I4.0+ model [8] when including environmental sustainability? The discussion in Section 2.2 suggests that comprehensive I4.0+ models should incorporate circular economy solutions in the flows and stock of material resources, together with both use of renewable natural resources and energy and the smart disposal of non-recyclable waste. The enhanced technocratic model would instead incorporate some updated versions of the "linear economy" (extract, consume, dispose) [53]. The analysis of drivers and barriers will allow to ground such intuitive featuring. The same analysis will clarify why other combinations are less interesting to consider in terms of general interpretative power, even if some real-world cases might be approximated to them, especially in transitory and hybrid states along paths of transformation [39]. Such other models could include either LPS aiming at environmental sustainability without a solid digital-related support, or LPS prioritizing digital innovation without environmentally sustainable solutions, as well as technocratic-monopolistic models incorporating true environmental sustainability solutions.

Recalling the framework presented in Section 2.2 and proposed in [8] as partial I4.0+ models for LPS sustainability transitions, we look at the drivers and barriers specifically related to the incorporation of environmental sustainability, thus obtaining a (more) comprehensive framework. Building on the same [8], Table 1 below presents a summary of the comprehensive I4.0+ model for LPSs' sustainable transitions.

Table 1. Drivers and barriers in LPS transitions to a comprehensive I4.0+ model.

\begin{tabular}{|c|c|c|}
\hline & Drivers & Barriers \\
\hline \multirow{2}{*}{ Value creation and economic actors } & $\begin{array}{l}\text { Interdependent new know-how nuclei } \\
\text { within and around smart } \\
\text { micro-manufacturing }\end{array}$ & $\begin{array}{l}\text { New transaction costs on crucial } \\
\text { information; technocratic models }\end{array}$ \\
\hline & $\begin{array}{l}\text { Control of closed loop processes, green } \\
\text { products as services, waste is wealth }\end{array}$ & $\begin{array}{l}\text { Digital-supported control of } \\
\text { delocalization of phases with high } \\
\text { environmental risks }\end{array}$ \\
\hline \multirow{2}{*}{ Value creation and societal-labor actors } & $\begin{array}{l}\text { Neo-makers driving a personalized use } \\
\text { of cyber-physical tools }\end{array}$ & $\begin{array}{l}\text { From skill polarization, and lack of } \\
\text { investments on new digital competencies }\end{array}$ \\
\hline & $\begin{array}{l}\text { Digital-powered skills in operations on } \\
\text { environment of processes/products use }\end{array}$ & $\begin{array}{l}\text { Till the exploitation of informal } \\
\text { workers in recycling dumpsites }\end{array}$ \\
\hline \multirow[b]{2}{*}{ Value redistribution and economic actors } & $\begin{array}{l}\text { Distributed provision of KIBS and } \\
\text { territorial servitization for SMEs }\end{array}$ & $\begin{array}{l}\text { Digital-based dominance of big players } \\
\text { within global value chains }\end{array}$ \\
\hline & $\begin{array}{l}\text { Their application to industrial } \\
\text { symbiosis, waste management } 4.0 \text {, } \\
\text { shared green value }\end{array}$ & $\begin{array}{l}\text { Digital supported monopolistic/illegal } \\
\text { control of natural resources/ sinks }\end{array}$ \\
\hline \multirow{2}{*}{ Value redistribution and economic actors } & $\begin{array}{l}\text { From territorial digital transformation } \\
\text { and quadruple-helix partnerships }\end{array}$ & $\begin{array}{l}\text { Digital divides, smart cities led by big } \\
\text { digital players and surveillance } \\
\text { approaches }\end{array}$ \\
\hline & $\begin{array}{l}\text { To quintuple-helix within sustainable } \\
\text { cities/RIS; CE seen as necessary to I4.0 }\end{array}$ & $\begin{array}{c}\text { Gated cities and regions and predatory } \\
\text { disposal of waste in local } \\
\text { non-protected areas }\end{array}$ \\
\hline
\end{tabular}

Source: Authors' elaboration on [8], Table.1, p. 7. Legenda: In plain characters: the factors directly related to digital transformation according to [8]; in bold: a present elaboration on those pertaining to digital transformations combining with or hindering environmental sustainability solutions.

Here, the drivers of and barriers to LPSs' sustainable transitions vary depending on whether we consider value creation for business actors, value creation for workers, value capture for business actors, and value capture for social actors.

Some considerations illustrate the original contents of Table 1. 
(a) Industry 4.0 technologies allow potentially large-scale economies in production and administrative costs. This may be seen as contributing to environmental sustainability: less for more. More specifically, different pools of those technologies may allow an automated control and a selective treatment of closed loop processes of reduction of material and energy losses, reusing, recycling, and remanufacturing [56]. Many types of waste within the linear economy processes can become sources of wealth thanks to the enhanced extractive, selective, and real-time networked solutions allowed by such technologies, whether within single firms or along local value chains. Furthermore, revenues may increase with the possibility to adapt to a growing demand of greener products, to the reuse of end-oflife products and to digital-based business models that combine co-creative producerconsumer relations and products as (partially) a service. Nonetheless, the opportunity cost might be not low enough for a full adoption of integrated solutions. This depends also on the possibility to scale up applications or distribute fixed costs. Larger firms have an advantage here if SMEs are not supported by an appropriate territorial servitization. Of course, LPSs may host collaborative sets of both SMEs and larger firms. However, the crucial point is the competition coming from the possibility to organize a low-cost linear alternative with the help of digital platforms [53]. This will imply the delocalization of phases of production or of recycling end-of-life products that have heavy and not easily reducible environmental impacts to places where the control of environmental risks is low or can be avoided, together with low labor costs, etc., usually to regions in the Global South. A strategic top-down control of digital platforms makes these operations easier, leaving at home the greener phases with related possibility of green washing campaigns [53]. Consequently, the opportunity costs for the enhanced I4.0+ model increase, directly within an LPS or indirectly given the clear competitive advantage of the technocratic model in adopting the delocalization solutions.

(b) An open organization made by a multiplicity of actors and oriented to combine digital-based and environmental sustainability solutions include many workers that operate at the interface between the environment, the phases of production, and the use of products. Let us think of the workers in waste management services [53]. They have a personal knowledge of the environment, and if supported by I4.0+ technologies and appropriate skills, can act to provide immediate feedback and suggestions, with the technologies possibly also alleviating the riskier and dirtier parts of such jobs. An alternative that appears consistent with the technocratic model is a combination of distant control rooms and distributed sensors, with the use of workers on the field for quite unqualified service jobs and the outsourcing of recycling to delocalized dump sites where armies of informal workers operate in horrible conditions [53].

(c) Territorial servitization is defined as a distributed, locally anchored, and personalized provision of knowledge-intensive business services (KIBS) to spatially bound and specialized SMEs in LPS. KIBS enable, support, and expand LPSs' internal competence capabilities [57]. It contributes to value creation related to the development of digitally based service solutions for enhancing processes and product performance. It helps value capture for SMEs as well, giving them a source of countervailing power against the dominance of big digital players within global value chains. KIBS could also include services that help the organization of close loops within or among value chains sharing a common localization, such as in models of green industrial parks and industrial symbiosis $[31,33,34]$, or services placed at the interface between local value chains, residential well-being, and waste management, enhanced by digital-supported solutions [53] (Chapter 6). Any successful LPS enjoys a certain degree of market power, although distributed and contestable in the long run [7]. However, its capability to capture the value created within the system and to use it as green shared value depends on collective actions supported by trust and corporate responsibility, not only social but also environmental [58]. In addition to transaction and fixed costs, the barriers to a sustainable transition are created by the competing alternative represented, within an LPS or much more efficiently within the technocratic model, 
by the private capture of the collectively produced value thanks to a digital-supported monopolistic control of both the sources of natural resources and waste sites $[55,59]$.

(d) Finally, we have already introduced the questions of governance and partnerships for projects of systemic innovation in LPS and their territories. We have recalled models of the quintuple helix and sustainable RIS, incorporating environmental sustainability in terms of actors, methods, and goals. Here, two further issues must be addressed. The first concerns the "directionality" of governance in dealing with green priorities: what public actors and their policies, at different levels, including context-making regulations, subsidies, and taxes, should pursue [31]. Specifically, the main direction concerns the necessity to support the link between I4.0+ and circular economy (CE) solutions in LPSs, cities, and RISs, not only because CE gives digital-related technologies an enormous field of local applications and business opportunities [60]. Solutions that pursue Industry 4.0 solutions without CE would deliver further cycles of unsustainable economic growth, with our planet being unable to support it, thereby accelerating a process destined for catastrophic outcomes and jeopardizing human liveability. The blind pursuit of economic growth at all costs must lose its traction. From local to global levels, there are options, as we discuss, that head to very different outcomes, namely "Stairway to Heaven or Highway to Hell" [53] (Chapter 8). The second issue relates to smart cities led by big digital players, surveillance approaches, and globally monopolistic districts [59,61]. They might deliver social divides with gated communities, where the liveability of the well-offs is protected, and the predatory disposal of waste in non-protected areas by actors able to exploit monopolistic positions and possibly to mobilize illegal, if not criminal, channels [54].

\section{Towards a Study of LPSs' Transitions towards Comprehensive I4.0+ Models}

Combinations of the drivers of and barriers to LPSs' sustainable transitions summarized in Table 1 identify different paths for LPSs engaged in technological and environmental change. The ideal typical model corresponding to the combination of specific complementary drivers on the left-hand side column of Table 1 could characterize comprehensive I4.0+ models. Given the complexity and uncertainties associated with I4.0+ transitions, cases of swift rerouting or of direct emergence of LPS fully adhering to comprehensive models should be considered highly improbable. Therefore, from an interpretative point of view, one must consider transition paths involving partial or hybrid I4.0+ states, as well as paths diverging from such I4.0+ models and either pointing to a decline or embracing a technocratic-monopolistic alternative.

In what follows, we seek to draft a model of sustainability transitions led by I4.0+ in LPSs and to exemplify it with reference to some case studies.

\subsection{A Taxonomy of I4.0+ Transitions in LPSs}

Recalling Table 1 above, the four boxes of the left column suggest the possibility of a couple of partial I4.0+ transition paths with different starting points and directions of evolution. We identify four possible paths by combining low to high levels of digital and economic drivers with low to high levels of green and social drivers. Figure 1 represents the transition opportunities of LPSs to I4.0+, starting from four possible initial states.

Focusing on rerouting and leaving aside birth conditions [62], we consider the hypothetical initial states of two ideal types of well-grown LPSs, depending on their core specializations and know-hows. In quadrant IV, we find LPSs characterized by a pool of differentiated natural and cultural resources (e.g., bio-economy specializations, tourism districts, etc.) being associated more easily with bio- and cultural paths. In quadrant II, we find LPSs characterized by highly automated processing (e.g., mineral-based products and mechanical industries, ICT clusters, etc.). 


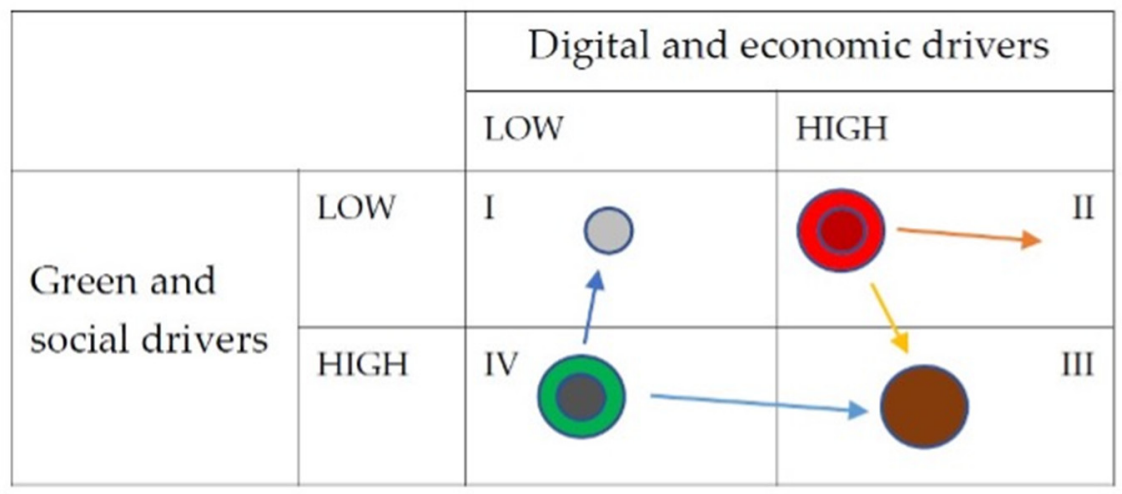

Figure 1. The LPS transitions framework. Source: original elaboration by the Authors.

What paths have these different LPSs opened in front of them? Quadrant III should be seen as the aspiration for both types of LPSs to reach a comprehensive realization of I4.0+. But what could be the transformation paths to reroute LPSs from either II or IV towards III?

Let us consider four possibilities (with the help of the figure). For the bio-cultural typology, virtuous evolutions point to a clear strengthening and integration of digital and economic drivers that combine with the original strength of the green and social drivers. Vice versa, the virtuous evolutions of the automatization typology point towards an increasing absorption of green and social drivers in synergy with the original strength of the digital and economic drivers. Both evolutions tend to gravitate around a comprehensive I4.0+ model in quadrant III.

However, such transitions can be undermined by the barriers summarized in the right column of Table 1 . They impinge on the trajectories in various ways. They might slow down the speed of change along the same directions or they might force a change of direction. In this second case, we argue that there are two main changes to contemplate, one for each typology of partial I4.0+, beyond the possibility of decline for both. The LPS of the bio-cultural typology could suffer an inability to integrate robustly the digital and economic drivers. The result of this would not be, at least in a longer run, a quasi-steady state within the IV quadrant. We have argued in Section 3 that circular-economy solutions tend to be weak without the integration of digital solutions. Such weakness implies that LPS will either decline (represented in Figure 1 by the smaller shape inside the larger contour) or fall in non-environmentally friendly solutions brought about by either local actors trying to survive economically or external actors looking for domination or predation. In Figure 1, this trajectory is represented by the shift from quadrant IV to quadrant I.

On the other side, the LPS characterized by automatization could suffer the symmetric inability to integrate green and social drivers. Again, this would not be consistent with a long-run quasi-steady state. We have argued that this inability directly implies a loss of many business opportunities in green markets and procurements. Facing the competition of enhanced I4.0+ LPS or of large firms of the technocratic model, one possibility is decline (the shrinkage of the area) and another is for the LPS to accelerate growth towards deeper digital solutions associated with global value chains of the technocratic model (digitalbased linear economy). This trajectory is represented by the shift within quadrant II to a more extreme corner.

\subsection{Case Studies}

This sub-section presents some exemplary case studies that help portray what sustainable transitions LPSs could embark on, depending on their starting state, as in Figure 1, to move more or less successfully towards comprehensive I4.0+ outcomes. The cases are just illustrative; that is, they have been selected neither to validate the framework nor to bring qualifications to it. Nonetheless, the profiling of the states and dynamics of these LPSs both clarifies what types of empirical applications the framework can have and opens to an extension of empirical research. 
The first case study that we refer to considers the transition of an LPS led by mediumto-large firms in the paper and pulp industry of a Swedish region [9]. In sectoral terms, it would appear to be a bio-cultural type. However, its industrial tradition pivots around a mass-production model, which is more typical of the other type. The case study makes explicit the four attributes that are implied by place-based green transitions in LPS, that we have introduced in Section 2.2. Business- and institutional-based initiatives try to push the LPS towards environmental innovation aimed at reconciling a reduced use of natural resources with economic growth. In this case, innovation concerns the main material input featuring the LPS under study, which is wood and, more generally, forestry. Pulled by knowledge transversality, this LPS managed to convert the renewable natural resource to productions that blend digital and environmental technologies by "creating a regional forest-based bio-economy" [9].

The paper illustrating a comparison of the ceramic district of Sassuolo and the leathertanning district of Arzignano provides an example of how two strong Italian industrial districts have adopted different strategies [33]. Both IDs are champions of sectors of made in Italy and have been facing environmental pressures for a long time. The paper does not go into detail on Industry 4.0 issues, because it was written at the beginning of the 2010s. However, a greater technological dynamism seems to be shown by Sassuolo, combining the production processes and the products with greening strategies and local environment care. A recent study [63] and a cursory reading of present-day websites confirms that the ceramic district is heavily engaged in I4.0+ applications within production processes. In the Arzignano case, there is definitely a certain level of technological dynamism, led by the necessity to assure the highest quality of the leather and to constantly improve the local environmental impacts of the industry. However, the penetration of automatization tends to be slowed by the natural lack of uniformity of the main raw material, that is, animal hides. A recent study [64] and a cursory reading of present-day grey sources talks about difficult and not-yet-accomplished attempts of application of I4.0+ solutions for increasing circular economy outcomes within core production processes. In summary, [33] points to the main drivers in the greening paths of the two districts: "Comparing the roles of district players in promoting and acting on sustainable strategies, the analysis of the Sassuolo district shows a bottom-up approach to facing environmental pressures, in which leading firms play a fundamental role in the evolution of the whole district, with a cooperative approach among different actors. Also, in the Arzignano district, the key role of the network of local firms and of the traditional relational governance structure emerges: the approach towards sustainability has also been influenced by the 'command \& control' measures of the authorities and by strong institutional support" [33] (p. 46). Considering the sectoral specializations in transition paths, the Arzignano district could be associated to a bio-cultural type and the Sassuolo district to an automatization type. The heuristic application of Figure 1 suggests that Sassuolo is an LPS that has covered an accomplished transition to a quite comprehensive I4.0+ model, with leading digital and economic drivers able to consistently integrate green and social drivers. Arzignano's approach to I4.0+ appears to be led by a focus on a green transition, with some difficulties that slow down an accomplished integration of digital and economic drivers. The entry in the gravitation field of a comprehensive I4.0+ model is possible, but retrogressive paths cannot be excluded.

\section{Conclusions and a Look Forward}

The novel conceptual framework presented in this paper provides a tool to generate taxonomical tables of LPSs undergoing different types of sustainability transitions. Indeed, the drivers and barriers identified in Table 1 and their combinations in Figure 1 refer implicitly to open and evolving varieties of factors and contexts. They concern, for example, the varieties in RIS, innovative milieus, quintuple helix partnerships, hybrid organizations within those partnerships, the policies, and the more general institutional context regulating individual and collective projects that involve combinations of digital, green, and social innovations that are usually adaptive but are sometimes more disruptive $[12,43,45,48]$. 
This leads to some conclusive remarks on policies towards digital-led or digital-related sustainable transitions in LPSs. The multi-scalarity of governance and policy translates into a need for nested strategies where the local declination of national and international priorities respects the specificities of the social, economic, and ecological conditions. This requires a shift away from either pure top-down or pure bottom-up approaches, and the implementation of a truly subsidiarity principle that allows the adoption and adaptation of digital and sustainable technologies to marry with the core specializations of the LPSs and their transformations. Transitions to comprehensive I4.0+ models require as much national and international vision as local commitment and determination, as in the Swedish case study [9]. For instance, the dystopic outcome of delocalizing ever-dirtier waste could be avoided by regulation, monitoring, and policing, rather than left to individual incentives and decisions [53].

I4.0+ transitions are manifold depending on the nature of the core specializations of the LPS at some intermediate evolutionary step (in Figure 1, the initial states); the latter will decide what opportunities and necessary changes the LPS must undergo to accomplish a shift to the next technological paradigm [62].

LPSs that have acquired a strong technological knowledge base might be tempted to continue along a path-dependent trajectory, reinforcing their digital base. This business-led approach could capture local and regional policy makers who have vested interest in a local system of relations that has worked for them and for the place for a while [4]. National or international (the EU level is exemplary in this respect) levels of policy makers must therefore push for a sustainable agenda that forces some fundamental and necessary changes, for example, in terms of alternative energy, electrification, or plastic bans [5]. The necessity of transition can develop a local sensitivity to priorities linked to the sustainable agenda and trigger collective actions that target desirable changes, matching the social, economic, and ecological conditions of the place $[13,31,60]$.

On the other hand, LPSs that show a specialization in bio-based and cultural assets will more easily embrace a green agenda that strengthens their business model and enriches the resources their specializations depend on. Ignoring the sea change that digitalization will bring across the industry could threaten the longer-term survival of these LPSs. A lack of connectivity, visibility, or digital literacy can isolate the LPS or erode its competitiveness. Here, pressures to endorse the digital change might be forced on the place by monopolist digital providers seeking new markets. However, necessary changes need to be driven by public investment in digital infrastructures that have an enabling function for equity and fairness. Like public goods, the supply of these components requires public intervention that can be at the national (e.g., 5G) or more local level (e.g., free WIFI) [4].

Transitions to a comprehensive I4.0+ model will proceed along different paths for LPSs, depending on their industrial historical and embedded nature and dynamics. For successful transitions, local stakeholders, including policy makers and businesses, have the duty and opportunity to shape the technological and ecological change to the needs of the place, identifying the unique features of its transition path, but also nesting change in national systemic visions that require large investment, a long-time horizon, and careful considerations of the possible externalities and trade-offs. Therefore, transitions to digitally enabled and greener systems would need to engage multi-scalar actors and actions, for instance investment in renewable energy sources that can allow a country to gain control over the quantity and cost of its energy (e.g., wind turbines or photovoltaic panels), whilst distributing energy production at the capillary level. LPSs would more willingly risk-share their decisions and investments because they are operating within a national level endeavor to embrace technological and ecological change [24].

The novel conceptual framework on sustainability transitions in contemporary LPSs towards comprehensive I4.0+ models (summarized in Table 1 and Figure 1) presented in this paper offers opportunities for building empirical analyses with apposite case studies. They will broaden and enrich our understanding of how LPSs may aspire to transition to outcomes that reconcile smart, social, and green goals. The cases discussed in the paper were 
retrieved from the current literature to illustrate the applicability of the transition framework to real-world LPSs and, therefore, its broader value, when analyzing what transitions LPSs actually face and to what outcome they lead.

Despite referring foremost to advanced economies and to the EU institutional context, this LPS transition framework might be adapted and expanded to contexts and case studies in new industrialized and developing economies $[43,59,60,65]$, also considering initial states of generally low degrees in local drivers. In those regions and countries, the local trade-offs between smart goals and the other goals of sustainability might be more extreme, describing transition paths whose positive outcomes depend on narrower sets of place-based and upper-level-specific conditions. These studies will allow for a constant validation of- and further progress on- the definition and application of positive and normative findings on sustainability transitions in LPSs.

Author Contributions: M.B. and L.D.P. are the sole authors of this paper and have worked jointly to all its parts and sections. All authors have read and agreed to the published version of the manuscript.

Funding: This research received no external funding.

Institutional Review Board Statement: Not applicable.

Informed Consent Statement: Not applicable.

Data Availability Statement: Not applicable.

Conflicts of Interest: The authors declare no conflict of interest.

\section{References}

1. De Propris, L.; Bailey, D. Industry 4.0 and Regional Transformations; Routledge: London, UK, 2020.

2. Schwab, K. The Fourth Industrial Revolution; World Economic Forum: Geneva, Switzerland, 2016.

3. Hacklin, F.; Marxt, C.; Fahrni, F. Coevolutionary cycles of convergence: An extrapolation from the ICT industry. Technol. Forecast. Soc. Chang. 2009, 76, 723-736. [CrossRef]

4. McCann, P.; Soete, L. Place-Based Innovation for Sustainability; Publications Office of the European Union: Luxemburg, 2020.

5. Breque, M.; De Nul, L.; Petridis, A. Industry 5.0. Towards a Sustainable, Human-Centric and Resilient European Industry; Publication Office of the European Union: Luxemburg, 2021.

6. Geels, F.W. The multi-level perspective on sustainability transitions: Responses to seven criticisms. Environ. Innov. Soc. Transit. 2011, 1, 24-40. [CrossRef]

7. Becattini, G.; Bellandi, M.; De Propris, L. (Eds.) Critical Nodes and Contemporary Reflections on Industrial Districts: An Introduction. In A Handbook of Industrial Districts; Edward Elgar: Cheltenham, UK, 2009; pp. xv-xxxv.

8. Bellandi, M.; De Propris, L.; Santini, E. A Place-Based View on Industry 4.0 in Local Productive Systems. L'industria 2020, 41, 51-69.

9. Ramirez, P. Sustainable manufacturing: Creating a regional forest-based bio-economy. In Industry 4.0 and Regional Transformations; De Propris, L., Bailey, D., Eds.; Routledge: London, UK, 2020; pp. 97-111.

10. Bailey, D.; Pitelis, C.; Tomlinson, P. Strategic management and regional industrial strategy: Cross-fertilization to mutual advantage. Reg. Stud. 2020, 54, 647-659. [CrossRef]

11. Carayannis, E.G.; Barth, T.D.; Campbell, D.F. The Quintuple Helix innovation model: Global warming as a challenge and driver for innovation. J. Innov. Entrep. 2012, 1, 2. [CrossRef]

12. Cooke, P. Regional Innovation Systems, Clean Technology \& Jacobian Cluster-Platform Policies. Reg. Sci. Policy Pract. 2008, 1 , 23-45.

13. Lehmann, M.; Christensen, P.; Johnson, B. Partnerships and Sustainable Regional Innovation Systems: Special Roles for Universities? In Facilitating Sustainable Innovation through Collaboration; Sarkis, J., Cordeiro, J., Vazquez Brust, D., Eds.; Springer: Dordrecht, The Netherlands, 2010; pp. 41-58.

14. World Commission on Environment and Development. Our Common Future; UN: New York, NY, USA, 1987.

15. UNEP. Making Peace with Nature: A Scientific Blueprint to Tackle the Climate, Biodiversity and Pollution Emergencies; United Nations Environment Programme: Nairobi, Kenya, 2021.

16. Agyeman, J. Introducing Just Sustainabilities: Policy, Planning and Practice; Zed Books: London, UK, 2013.

17. Autor, D.H. Why Are There Still So Many Jobs? The History and Future of Workplace Automation. J. Econ. Perspect. 2015,29, 3-31.

18. Corò, G.; Plechero, M.; Rullani, F.; Volpe, M. Industry 4.0 technological trajectories and traditional manufacturing regions: The role of knowledge workers. Reg. Stud. 2021, 55, 1681-1695. [CrossRef]

19. EU Parliament. Industry 4.0: Digitalisation for Productivity and Growth; Briefing: Bruxelles, Belgium, 2015. 
20. Barca, F.; McCann, P.; Rodríguez-Pose, A. The case for regional development intervention: Place-based versus place-neutral approaches. J. Reg. Sci. 2012, 52, 134-152. [CrossRef]

21. Perez, C. Technological revolutions and techno-economic paradigms. Camb. J. Econ. 2010, 34, 185-202. [CrossRef]

22. Truffer, B.; Coenen, L. Environmental Innovation and Sustainability Transitions in Regional studies. Reg. Stud. 2012, 46, 1-21. [CrossRef]

23. Sjøtun, S.G.; Njøs, R. Green reorientation of clusters and the role of policy: 'the normative' and 'the neutral' route. Eur. Plan. Stud. 2019, 27, 2411-2430. [CrossRef]

24. De Propris, L.; Bailey, D. Pathways of regional transformation and Industry 4.0. Reg. Stud. 2021, 55, 1617-1629. [CrossRef]

25. Torre, A. Territorial development and proximity relationships. In Handbook of Regional and Development Theories, 2nd ed.; Capello, R., Nijkamp, P., Eds.; Edward Elgar Publishers: Cheltenham, UK, 2019; pp. 326-343.

26. Asheim, B.; Isaksen, A.; Trippl, M. Advanced Introduction to Regional Innovation Systems; Edward Elgar: Cheltenham, UK, 2019.

27. Becattini, G. Beyond geo-sectoriality: The productive chorality of places. Investig. Reg. 2015, 32, 31-41.

28. Crouch, C.; Le Galès, P.; Trigilia, C.; Voelzkow, H. (Eds.) Changing Governance of Local Economies: Responses of European Local Production Systems; Oxford University Press: Oxford, UK, 2004.

29. Sólvell, Ö. Construction of the Cluster Commons. In The Oxford Handbook of Local Competitiveness; Audretsch, D., Link, A., Lindestein Walshok, M., Eds.; Oxford University Press: Oxford, UK, 2015; pp. 84-101.

30. Santoalha, A.; Boschma, R. Diversifying in green technologies in European regions: Does political support matter? Reg. Stud. 2021, 55, 182-195. [CrossRef]

31. EU Commission. Connecting Smart and Sustainable Growth through Smart Specialization-A Practical Guide for ERDF Managing Authorities; Publication Office of the European Union: Luxemburg, 2012.

32. Hermans, F.L.P. Bioclusters and Sustainable Regional Development. In Rethinking Clusters. Place-Based Value Creation in Sustainability Transitions; Sedita, S.R., Blasi, S., Eds.; Springer Nature Switzerland AG: Cham, Switzerland, 2021; pp. 81-91.

33. Da Ronch, B.; Di Maria, E.; Micelli, S. Clusters go green: Drivers of environmental sustainability in local networks of SMEs. Int. J. Inf. Syst. Soc. Chang. 2013, 4, 37-52. [CrossRef]

34. Mazzanti, M.; Zoboli, R. Embedding environmental innovation in local production systems: SME strategies, networking and industrial relations: Evidence on innovation drivers in industrial districts. Int. Rev. Appl. Econ. 2009, 23, 169-195. [CrossRef]

35. Kebir, L.; Crevoisier, O.; Costa, P.; Peyrache-Gadeau, V. (Eds.) Sustainable Innovation and Regional Development: Rethinking Innovative Milieus; Edward Elgar: Cheltenham, UK, 2017.

36. Hassink, R.; Isaksen, A.; Trippl, M. Towards a comprehensive understanding of new regional industrial path development. Reg. Stud. 2019, 53, 1636-1645. [CrossRef]

37. Bellandi, M.; Ruiz Fuensanta, M.J.; Santini, E. Factors of Environmental Sustainability in Italian Industrial Districts: A Composite Environmental Sustainability Index. In Rethinking Clusters. Place-Based Value Creation in Sustainability Transitions; Sedita, S.R., Blasi, S., Eds.; Springer Nature Switzerland AG: Cham, Switzerland, 2021; pp. 111-124.

38. Beer, A.; McKenzie, F.; Blazec, J.; Sotarauta, M.; Ayres, S. Every Place Matters: Towards Effective Place-Based Policy; Regional Studies Policy Impact Books; Taylor \& Francis: Abingdon, UK, 2020.

39. Bellandi, M.; Plechero, M.; Santini, E. Forms of place leadership in local productive systems: From endogenous rerouting to deliberate resistance to change. Reg. Stud. 2021, 55, 1327-1336. [CrossRef]

40. Bellandi, M. Factors Supporting or Hindering the Place-based Structure of Commons in Local Productive Systems. Region 2021, 8 , 1-14. [CrossRef]

41. Cai, Y.; Etzkowitz, H. Theorizing the Triple Helix model: Past, present, and future. Triple Helix 2020, 7, 189-226. [CrossRef]

42. Carayannis, E.G.; Rakhmatullin, R. The quadruple/quintuple innovation helixes and smart specialisation strategies for sustainable and inclusive growth in Europe and beyond. J. Knowl. Econ. 2014, 5, 212-239. [CrossRef]

43. Yun, J.J.; Liu, Z. Micro- and Macro-Dynamics of Open Innovation with a Quadruple-Helix Model. Sustainability 2019, $11,3301$. [CrossRef]

44. Gerstlberger, W. Regional innovation systems and sustainability-Selected examples of international discussion. Technovation 2004, 24, 749-758. [CrossRef]

45. Aoyama, Y.; Parthasarathy, B. When both State and Market fail: Inclusive Development and Social Innovation in India. Area Dev. Policy 2018, 3, 330-348. [CrossRef]

46. Schwerdtner, W.; Siebert, R.; Busse, M.; Freisinger, U.B. Regional Open Innovation Roadmapping: A New Framework for Innovation-Based Regional Development. Sustainability 2015, 7, 2301-2321. [CrossRef]

47. Blix Germundsson, L.; Augustinsson, S.; Lidén, A. Collaboration in the Making-Towards a Practice-Based Approach to University Innovation Intermediary Organisations. Sustainability 2020, 12, 5142. [CrossRef]

48. Trencher, G.; Yarime, M.; McCormick, K.B.; Doll, C.N.H.; Kraines, S.B. Beyond the third mission: Exploring the emerging university function of co-creation for sustainability. Sci. Public Policy 2014, 41, 151-179. [CrossRef]

49. Hoppe, T.; Miedema, M.A. Governance Approach to Regional Energy Transition: Meaning, Conceptualization and Practice. Sustainability 2020, 12, 915. [CrossRef]

50. Cooke, P. Green governance and green clusters: Regional \& national policies for the climate change challenge of Central \& Eastern Europe. J. Open Innov. 2015, 1, 1. 
51. Chaminade, C.; Bellandi, M.; Plechero, M.; Santini, E. Understanding processes of path renewal and creation in thick specialized regional innovation systems. Evidence from two textile districts in Italy and Sweden. Eur. Plan. Stud. 2019, 27, 1978-1994.

52. Young, R.F. "Free cities and regions"-Patrick Geddes's theory of planning. Landsc. Urban Plan. 2017, 166, 27-36. [CrossRef]

53. Mavropoulos, A.; Waage Nilsen, A. Industry 4.0 and Circular Economy: Towards a Wasteless Future or a Wasteful Planet? John Wiley and Sons: Chichester, UK, 2020.

54. Walters, R. Eco Mafia and Environmental Crime. In Crime, Justice and Social Democracy. Critical Criminological Perspectives; Carrington, K., Ball, M., O’Brien, E., Tauri, J.M., Eds.; Palgrave Macmillan: London, UK, 2013; pp. 281-294.

55. Biggeri, M.; Ferrannini, A. Sustainable Human Development: A New Territorial and People-Centred Perspective; Palgrave Macmillan: London, UK, 2014.

56. Enyoghasi, C.; Badurdeen, F. Industry 4.0 for sustainable manufacturing: Opportunities at the product, process, and system levels. Resour. Conserv. Recycl. 2021, 166, 105362. [CrossRef]

57. Gomes, E.; Bustinza, O.F.; Tarba, S.; Khan, Z.; Ahammad, M. Antecedents and implications of territorial servitization. Reg. Stud. 2019, 53, 410-423. [CrossRef]

58. Alberti, F.G.; Belfanti, F. How to Successfully Translate Shared Value Agendas into Action? Evidences from the Case of 21 Invest. In Rethinking Clusters. Place-Based Value Creation in Sustainability Transitions; Sedita, S.R., Blasi, S., Eds.; Springer Nature Switzerland AG: Cham, Switzerland, 2021; pp. 143-158.

59. Cooke, P. The Lithium Wars: From Kokkola to the Congo for the 500 Mile Battery. Sustainability 2021, 13, 4215. [CrossRef]

60. Sabatini-Marques, J.; Yigitcanlar, T.; Schreiner, T.; Wittmann, T.; Sotto, D.; Inkinen, T. Strategizing Smart, Sustainable, and Knowledge-Based Development of Cities: Insights from Florianópolis, Brazil. Sustainability 2020, 12, 8859. [CrossRef]

61. Feldman, M.; Guy, F.; Iammarino, S. Regional Income Disparities, Monopoly E Finance; Working Paper; Birbeck, University of London: London, UK, October 2019; Volume 43.

62. Bellandi, M.; De Propris, L.; Santini, E. Endogenous Rerouting and Longevity in Systemic Organisations of Production. In Agglomeration and Firm Performance; Belussi, F., Hervas-Oliver, J.L., Eds.; Springer International Publishing AG: Cham, Switzerland, 2018; pp. 207-221.

63. Garcia-Muiña, F.E.; González-Sánchez, R.; Ferrari, A.M.; Settembre-Blundo, D. The Paradigms of Industry 4.0 and Circular Economy as Enabling Drivers for the Competitiveness of Businesses and Territories: The Case of an Italian Ceramic Tiles Manufacturing Company. Soc. Sci. 2018, 7, 255. [CrossRef]

64. De Marchi, V.; Di Maria, E. Environmental Upgrading and Suppliers' Agency in the Leather Global Value Chain. Sustainability 2019, 11, 6530. [CrossRef]

65. Omobhude, C.; Chen, S.-H. Social Innovation for Sustainability: The Case of Oil Producing Communities in the Niger Delta region. Sustainability 2019, 11, 6767. [CrossRef] 